\title{
ANALISIS PEMECAHAN MASALAH MATEMATIKA DALAM DISCOVERY LINK MAP
}

\author{
Mega Nur Aini ${ }^{1}$, Retno Marsitin ${ }^{2}$, Trija Fayeldi ${ }^{3}$ \\ ${ }^{1,2,3}$ Pendidikan Matematika, Universitas Kanjuruhan Malang, Indonesia \\ ${ }^{1}$ megaaain@gmail.com \\ 2 \\ mars_retno@unikama.ac.id \\ 3 trija_fayeldi@unikama.ac.id
}

\begin{abstract}
Abstrak:. Kemampuan pemecahan masalah matematika terdiri dari 4 langkah yaitu pemahaman masalah, perencanaan cara penyelesaian, pelaksanaan rencana dan memeriksa kembali. Tujuan penelitian adalah untuk mendeskripsikan tingkat kemampuan pemecahan masalah peserta didik dalam Discovery Link Map dan untuk mengetahui penyebab kesalahan peserta didik dalam menyelesaikan soal. Penelitian ini menggunakan penelitian kualitatif dan jenis penelitiannya adalah deskriptif-kualitatif. Subjek yang dianalisis adalah 8 peserta didik kelas X SMK Islam Gondanglegi. Prosedur pengumpulan data terdiri dari tes kemampuan pemecahan masalah, wawancara, dan dokumentasi. Instrumen penelitian tes dan wawancara dilakukan validasi oleh validator. Pengecekan keabsahan data dilakukan dengan triangulasi metode. Data penelitian yang terkumpul dianalisis dengan tahapan perekduksian data, penyajian data dan penarikan kesimpulan. Hasil dari penelitian yaitu hasil tes dan wawancara menunjukkan kriteria sangat baik terdapat 4 peserta didik, kriteria baik terdapat 6 peserta didik, kriteria cukup terdapat 4 peserta didik, kriteria kurang terdapat 4 peserta didik, dan tidak ada peserta didik yang tergolong kriteria sangat kurang. Persentase pada aspek memahami masalah adalah $87,03 \%$, pada aspek merencanakan penyelesaian adalah $85,18 \%$, pada aspek melaksanakan rencana adalah 79,62\%, dan pada aspek memeriksa kembali adalah $68,51 \%$. Kesimpulannya adalah kriteria sangat baik, kriteria baik, kriteria cukup, kriteria kurang, dan sangat kurang. Penyebab kesalahan peserta didik yaitu masih belum teliti dalam menentukan satuan dari jawaban yang diberikan, kurang memanfaatkan waktu dalam mengerjakan soal, lupa mengerjakan beberapa tahapan pemecahan masalah, dan masih belum paham sepenuhnya metode subsitusi dan metode eliminasi. Saran untuk penelitian selanjutnya dapat mengambangkan menjadi beberapa tingkatan yang lebih spesifik.
\end{abstract}

Kata Kunci: Discovery Link Map, Pemecahan Masalah Matematika.

Abstract : The ability to solve mathematical problems consists of four steps, namely understanding the problem, planning how to solve, implementing the plan and checking again. The purpose is to describe the level of problem solving ability of students in the Discovery Link Map and to determine the couse of student's mistakes in solving problems. This research used qualitative research and the type of research is descriptive-qualitative. The subjects were 8 students of class X at SMK Islam Gondanglegi. Data collection procedures consist of tests of problem solving skills, interviews, and documentation. The test and interview research instruments were validated by the validator. Checking the validity of the data is done by method triangulation. The research data collected were analyzed with the stages of data reduction, data presentation and drawing conclusions. The results of study which are the results of tests and interviews show that students who get very good criteria there are four students, good criteria there are six students, sufficient criteria there are four students, poor criteria there are four students, and there are no students classified as very poor criteria. The percentage on the aspect of understanding the problem is $87.03 \%$, planning a solution is $85.18 \%$, implementing the plan is $79.62 \%$, and on the re-cheching aspect is $68.51 \%$. The conclusions based on the result of this study obtained very good, good criteria, sufficient, poor, and very poor criteria. The couse of students mistakes are they have not been careful in determining the units of the answers given, they do not take the time to work on problems, forget to do some stages of problem solving, and still do not fully understand the method of substitution and elimination methods. The suggestions for next research can develop into several levels more specific.

Keywords : Discovery link map, Mathematics Problem Solving. 


\section{Pendahuluan}

Matematika adalah salah salah satu mata pelajaran yang mempunyai peranan penting dalam dunia pendidikan. Sutikno (2017) mengungkaplan bahwa banyak konsepi dari matematika yang digunakan pada bidang kimia, fisika, biologi, ekonomi, teknik dan astronomi untuk penyelesaian masalah sehari-hari. Hal itu merupakan acuan bahwa matematika menjadi ilmu yang penting dipelajari pada era modern saat ini. Kesumawati (dalam Mawaddah dan Anisha, 2015) menyatakan bahwa kemampuan pemecahan masalah adalah kemampuan menguraikan komponenkomponen yang diketahui dan ditanyakan, mampu merumuskan model matematika, dapat memilih rencana pemecahan dan mampu memeriksa kembali jawaban yang sudah diperoleh.

Polya dalam Yulianto, Suastika dan Fayeldi (2019) mengusulkan 4 tahap dalam melakukan pemecahan masalah matematika mencakup: (1) pemahaman masalah, (2) perencanaan cara penyelesaian, (3) pelaksanaan rencana, dan (4) memeriksa kembali. Pemecahan masalah polya dapat digunakan untuk memecahkan berbagai masalah dalam materi pelajaran. Salah satu materi yang dapat menggunakan pemecahan masalah Polya yaitu sistem persamaan linier tiga variabel.

Berdasarkan wawancara dengan guru matematika SMK Islam Gondanglegi, lebih dari $30 \%$ peserta didik masih kesulitan dalam memahami dan menyelesaikan soal cerita pada materi sistem persamaan linier tiga variabel. Ada beberapa kesulitan yang dialami peserta didik antara lain karena peserta didik kurang memahami masalah dengan cermat sehingga informasiinformasi penting tidak digunakan dalam menyelesaikan masalah dan juga kurang teliti dalam penyelesaian.

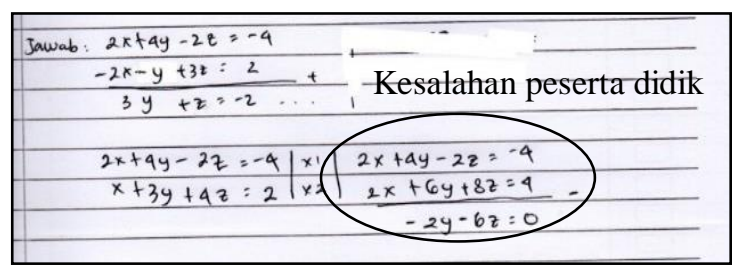

Gambar 1. Contoh Pengerjaan Soal Peserta Didik yang Kurang Teliti dalam Penyelesaian

Dari gambar 1. contoh pengerjaan soal tersebut peserta didik kurang teliti dalam melakukan eliminasi. Kesalahan peserta didik tersebut mengakibatkan peserta didik juga melakukan kesalahan pada tahap selanjutnya, sehingga berakibat himpunan penyelesaian soal tersebut juga salah.

Penelitian sebelumnya yang dilakukan Ramadhani (2017) tentang peningkatan kemampuan pemecahan masalah matematika peseta didik SMA melalui guided discovery learning berbantuan autograph menyatakan bahwa peningkatan kemampuan pemecahan masalah matematika peserta didik yang memperoleh guided discovery learning berbantuan autograph lebih meningkat daripada peserta didik yang memperoleh pembelajaran konvesional seperti biasa. Selain itu, penelitian Rosdianwinata (2015) tentang penerapan metode discovery untuk meningkatkan kemampuan pemecahan masalah matematika peserta didik menyatakan bahwa kemampuan pemecahan masalah peserta didik yang sudah melakukan pembelajaran dengan metode discovery tidak mengalami peningkatan hasil yang baik. Berdasarkan hasil penelitian dari dua peneliti tersebut, perlu dilakukan penelitian tentang discovery agar memperlihatkan pentingnya pembelajaran discovery untuk peningkatan hasil belajar peserta didik. Sedangkan menurut hasil pernelitian rosdianwinata metode discovery tidak mengalami peningkatan yang baik sehingga peneliti berusaha 
menerapkan pembelajaran matematika menggunakan Discovery link Map. Link map merupakan pembelajaran dengan materi yang kompleks dapat dikemas menjadi peta keterkaitan (link map) yang mudah untuk diolah dan dikontruksikan dalam pemikiran peserta didik (Marsitin, 2018).

\section{Metode Penelitian}

Penelitian ini menggunakan penelitian kualitatif dan jenis penelitian ini adalah penelitian deskriptif-kualitatif. Penelitian ini dilaksanakan untuk melakukan analisis terhadap kemampuan pemecahan masalah matematika dalam discovery link map di SMK Islam Gondanglegi Kabupaten Malang. Kehadiran peneliti dalam penelitian ini sangat penting karena data yang dikumpulkan harus berdasarkan fakta di lapangan dan peneliti juga sebagai instrumen utama. Penelitian ini dilaksanakan di SMK Islam Gondanglegi yang terletak di Jalan Ahmad Yani No. 01 Gondanglegi Kabupaten Malang. Pada penelitian ini, sumber data terdiri atas data primer dan data sekunder. Sumber data primer adalah tes hasil wawancara dengan subjek penelitian. Sumber data sekunder yang di kumpulkan adalah hasil tes kemampuan pemecahan masalah peserta didik pada materi sistem persamaan linier tiga variabel . subjek dari penelitian ini adalah peserta didik kelas X TBSM yang terdiri dari 18 peserta didik yang semuanya laki-laki. Peneliti menganalisis 8 peserta didik berdasarkan kriteria tingkat kemampuan pemecahan masalah pada Tabel 1 .

Tabel 1 Kriteria Tingkat Kemampuan Pemecahan Masalah

\begin{tabular}{cc}
\hline Nilai & Kriteria \\
\hline $85,00 \leq x \leq 100$ & Sangat Baik \\
$70,00 \leq x<85,00$ & Baik \\
$55,00 \leq x<70,00$ & Cukup \\
\hline
\end{tabular}

\begin{tabular}{cc} 
& \\
$40,00 \leq x<55,00$ & Kurang \\
$0 \leq x<40,00$ & Sangat Kurang \\
\hline
\end{tabular}

Sumber: Modifikasi Japa dalam Mawaddah dan Anisah (2015

Prosedur pengumpulan data yaitu tes kemampuan pemecahan masalah peserta didik, wawancara digunakan untuk mengamati secara langsung tingkah laku peserta didik saat diajukan pertanyaan dan validasi digunakan untuk mengvalidasi soal tes tulis dan RPP dengan model discovery link map. Analisis data terdiri dari perekdusian data, penyajian data dan penarikan kesimpulan. Pengecekan keabsahan data menggunakan triangulasi metode. Tahap penelitian ini terdiri dari tahap perencanaan penelitian, tahap pelaksanaan penelitian dan tahap analisis data. Pada tahap perencanaan, peneliti akan membuat RPP dengan model discovery link map, membuat tes tulis kemampuan pemecahan masalah peserta didik dan pedoman wawancara kemudian divalidasi oleh validator. Pada tahap pelaksanaan penelitian, yang pertama memberikan pemahaman tentang kemampuan pemecahan masalah dalam discovery link map pada materi sistem persamaan linier tiga variabel. setelah itu, dilakukan tes tulis untuk mengetahui kemampuan pemecahan masalah peserta didik dan wawancara berdasarkan kriteria tingkat kemampuan pemecahan masalah yang dimiliki oleh peserta didik. Pada tahap analisis data, akan dilakukan pengumpulan dan menganalisis data secara langsung dari subjek berupa tes tulis dan wawancara

\section{Hasil dan Pembahasan}

Hasil persentase kriteria tingkat kemampuan pemecahan masalah dari 18 peserta didik adalah $22,22 \%$ termasuk kriteria sangat baik, 33,33\% termasuk kriteria baik, 22,22\% termasuk kriteria cukup, 22,22 \% termasuk kriteria kurang, dan $0 \%$ termasuk kriteria sangat kurang. 
Berikut hasil pengerjaan soal dari sujek FL pada kriteria sangat baik

\begin{tabular}{|c|c|c|}
\hline \multicolumn{3}{|c|}{  } \\
\hline \multicolumn{3}{|c|}{ Merencanakan Penyelesaian } \\
\hline $\begin{aligned} \text { Misal: }:-x & =P \\
y & =l\end{aligned}$ & $\begin{aligned}-k & =2 \cdot(P+l) \\
72 & =2 \cdot(P+l) \\
\frac{72}{2} & =P+l \\
36 & =P+l \\
x & +y=36 \ldots .(1)\end{aligned}$ & $\begin{array}{l}-P=4+l \\
P-l=4 \\
x-y=4 \ldots \text {. }\end{array}$ \\
\hline \multicolumn{3}{|c|}{ Melaksanakan Rencana } \\
\hline $\begin{aligned} x+y & =36 \\
x-y & =4 \\
2 y & =32 \\
y & =\frac{32}{2} \\
y & =16\end{aligned}$ & $\begin{aligned} x+y & =36 \\
x+16 & =36 \\
x & =36-16 \\
x & =20\end{aligned}$ & $\begin{aligned} L & =P \times l \\
& =20 \times 16 \\
& =300\end{aligned}$ \\
\hline \multicolumn{3}{|l|}{ Memeriksa Kembali } \\
\hline $\begin{array}{l}k=2(P+l) \\
72=2(20+16) \\
72=2 \cdot(36) \\
7_{2}=72 \text { Benar }\end{array}$ & $\begin{array}{l}P=4+l \\
20=4+16 \\
20=20 \text { Benar }\end{array}$ & \\
\hline
\end{tabular}

\section{Gambar 2. Hasil Jawaban Subjek FL Soal} Nomor 1

Subjek FL pada soal nomor 1 mampu melakukan 4 tahapan pemecahan masalah dengan baik namun pada tahap melaksanakan rencana penyelesaian subjek FL tidak menuliskan satuan luas karena kurang teliti

Hasil pengerjaan soal dari subjek AFA pada kriteria Baik

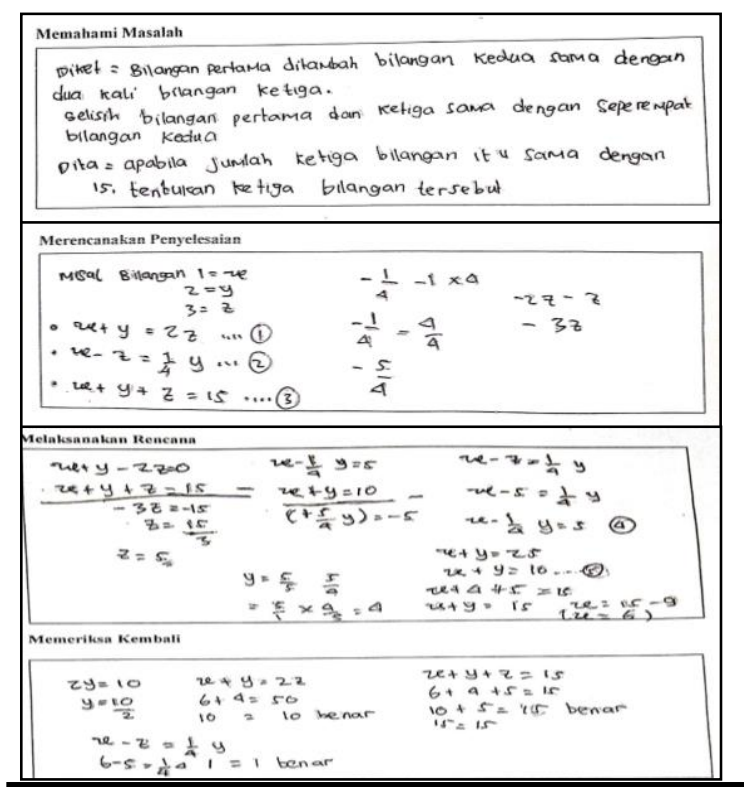

Pi: Mathematics Education Journal http://ejournal.unikama.ac.id/index.php/pmej
Gambarar 3. Hasil Jawaban Subjek AFA Soal Nomor 2

subjek AFA pada soal nomor 2 mampu melakukan 4 tahapan pemecahan masalah dengan lengkap subjek AFA mampu memahami masalah, merencanakan penyelesaian, melaksanakan rencana dan mampu memeriksa kembali dengan benar dan lengkap.

Hasil pengerjaan soal subjek ML pada kriteria Cukup

\begin{tabular}{|c|}
\hline Memahami Masalah \\
\hline 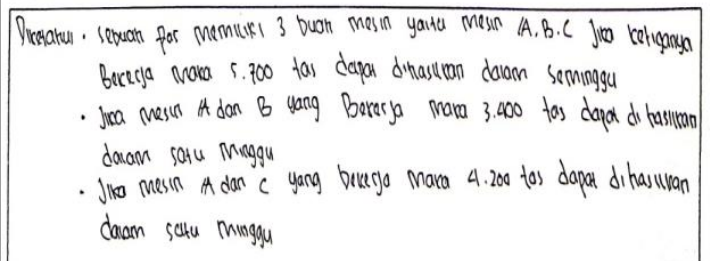 \\
\hline Dhanga : borcopa tas yang dihasikan tap mesin dalam \\
\hline
\end{tabular}

Gambar 4. Hasil Jawaban Subjek ML Soal Nomor 3

Subjek ML pada soal nomor 3 tidak mampu melakukan 4 tahapan pemecahan masalah dengan lengkap. Subjek ML hanya mampu melakukan 1 tahapan yaitu memahami masalah sedangkan pada tahap merencanakan penyelesaian, melaksanakan rencana dan memeriksa kembali subjek ML tidak menuliskan jawaban.

Hasil pengerjaan soal Subjek MRAR pada kriteria Kurang

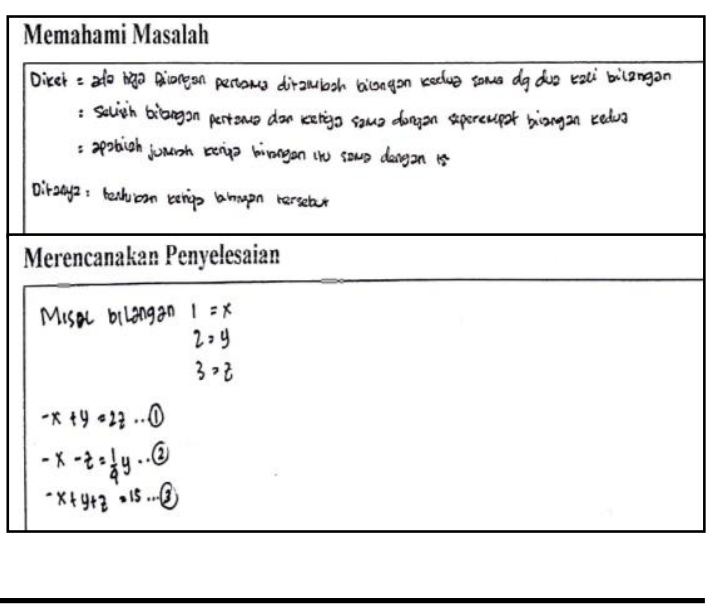


Gambar 5. Hasil Jawaban Subjek MRAR Soal Nomor 2

Subjek MRAR pada soal nomor 2 tidak mampu melakukan 4 tahapan pemecahan dengan lengkap, subjek MRAR hanya mampu melakukan 2 tahapan yaitu memahami masalah dan merencanakan penyelesaian.

Berdasarkan indikator pemecahan masalah peserta didik presentase pada aspek memahami masalah $87,03 \%$, pada aspek merencanakan penyelesaikan $85,18 \%$, pada aspek melaksanakan rencana $79,62 \%$, dan apada aspek memeriksa kembali $68,51 \%$. Berikut hasil skor kemampuan pemecahan masalah matematika peserta didik kelas X TBSM di SMK Islam Gondanglegi Kabupaten Malang.

\begin{tabular}{|c|c|c|c|c|}
\hline No & $\begin{array}{l}\text { Inisial } \\
\text { Nama }\end{array}$ & $\begin{array}{l}\text { Total } \\
\text { Skor }\end{array}$ & $\begin{array}{c}\text { Nilai } \\
\text { Akhir } \\
\text { (Rata- } \\
\text { rata) }\end{array}$ & Kategori \\
\hline 1. & FL & 280 & 93,33 & $\begin{array}{c}\text { Sangat } \\
\text { Baik }\end{array}$ \\
\hline 2. & RAS & 270 & 90 & $\begin{array}{c}\text { Sangat } \\
\text { Baik }\end{array}$ \\
\hline 3. & AYS & 260 & 86.67 & $\begin{array}{l}\text { Sangat } \\
\text { Baik }\end{array}$ \\
\hline 4. & $\mathrm{MF}$ & 260 & 86,67 & $\begin{array}{c}\text { Sangat } \\
\text { Baik }\end{array}$ \\
\hline 5. & DAI & 240 & 80 & Baik \\
\hline 6. & AFA & 230 & 76,67 & Baik \\
\hline 7. & MSD & 230 & 76,67 & Baik \\
\hline 8. & $\mathrm{NH}$ & 230 & 76,67 & Baik \\
\hline 9. & AFM & 210 & 70 & Baik \\
\hline 10. & AR & 210 & 70 & Baik \\
\hline 11. & ML & 200 & 66,67 & Cukup \\
\hline 12. & MT & 195 & 65 & Cukup \\
\hline 13. & MRSB & 180 & 60 & Cukup \\
\hline 14. & MSI & 180 & 60 & Cukup \\
\hline 15. & MS & 150 & 50 & Kurang \\
\hline 16. & MRAR & 140 & 46,67 & Kurang \\
\hline 17. & WN & 140 & 46,67 & Kurang \\
\hline 18. & MHM & 130 & 43.33 & Kurang \\
\hline
\end{tabular}

Tabel 2. Hasil Skor Kemampuan Pemecahan Masalah Matematika
Berdasarkan Tabel 2. Kesimpulan hasil skor kemampuan pemecahan masalah matematika peserta didik kelas X TBSM di SMK Islam Gondangkegi Kabupaten Malang sebagai berikut.

1. Kriteria Sangat Baik

Kriteria kemampuan sangat baik pada rentang nilai $85,00 \leq x \leq$ 100. Pada penelitian ini, kriteria sangat baik terdapat 4 peserta didik. Peserta didik pada kriteria sangat baik mampu memahami masalah merencanakan penyelesaian, melaksanakan rencana dan memeriksa kembali namun peserta didik kurang teliti dalam menuliskan satuan.

2. Kriteria Baik

Kriteria baik pada rentang nilai $70,00 \leq x<85,00$. Pada penelitian ini, kriteria baik terdapat 6 peserta didik. Peserta didik pada kriteria baik mampu memahami masalah, mampu merencanakan penyelesaian, mampu melaksanakan rencana namun hasil pengerjaan peserta didik pada tingkat ini sebagian besar tidak mampu memeriksa kembali jawaban.

3. Kriteria cukup

kriteria kemampuan cukup pada rentang nilai $55,00 \leq x<70,00$. Pada kriteria cukup terdapat 4 peserta didik. Peserta didik pada kriteria cukup mampu memahami masalah, mampu merencanakan penyelesaian tetapi tidak mampu melaksanakan rencana dan tidak mampu memeriksa kembali.

4. Kriteria Kurang

kriteria kemampuan kurang pada rentang nilai $40,00 \leq x<$ 55,00 . Pada kriteria kurang terdapat 4 peserta didik, Peserta didik pada kriteria kurang, subjek mampu memahami masalah, tidak mampu menyusun rencana penyelesaian, 
tidak mampu melaksanakan rencana, dan tidak mampu memeriksa kembali.

5. Kriteria Sangat Kurang

Kriteria kemampuan sangat kurang pada rentang nilai $0 \leq x<40,00$. Pada penelitian ini, tidak ada peserta didik yang berada pada kriteria sangat kurang.

Penyebab kesalahan yang dilakukan peserta didik adalah (1) kesalahan memahami soal (2) kesalahan menyusun rencana (3) kesalahan melaksanakan rencana dan (4) kesalahan memeriksa kembali solusi yang diperoleh. Penyebab kesalahan peserta didik pada kriteria sangat baik adalah peserta didik masih belum teliti dalam menentukan satuan dari jawaban yang diberikan. Penyebab kesalahan peserta didik pada kriteria baik adalah peserta didik saaat mengerjakan soal adalah kurang memanfaatkan waktu dalam mengerjakan soal. Penyebab kesalahan peserta didik pada kriteria cukup dikarenakan lupa mengerjakan beberapa tahapan pemecahan masalah. Penyebab kesalahan peserta didik pada kriteria kurang adalah dikarenakan peserta didik belum memahami tentang materi sistem persamaan linier tiga variabel dan pada saat mengerjakan soal adalah pada tahap melaksanakan rencana peserta didik masih belum paham sepenuhnya metode subsitusi dan metode eliminasi yang digunakan untuk mengerjakan soal. Dari 18 subjek penelitian, terdapat 14 subjek yang berhasil memenuhi KKM, hal itu membuktikan bahwa Discovery Link Map sangat berpengaruh terhadap peningkatan hasil kemampuan pemecahan masalah peserta didik yang sebagian besar mendapatkan nilai di atas KKM.

\section{Kesimpulan}

Kriteria tingkat kemampuan pemecahan masalah peserta didik kelas $\mathrm{X}$
TBSM SMK Islam Gondanglegi Kabupaten Malang diklasifikasikan menjadi 5 kriteria yaitu: kriteria sangat baik terdapat 4 peserta didik, kriteria baik terdapat 6 peserta didik. Kriteria cukup terdapat 4 peserta didik, kriteria kurang terdapat 4 peserta didik, dan tidak ada peserta didik pada kriteria sangat kurang. Berdasarkan indikator kemampuan pemecahan masalah peserta didik persentase pada aspek memahami masalah adalah $87,03 \%$, peserta didik mampu memahami masalah, pada aspek merencanakan penyelesaian adalah $85,18 \%$ peserta didik mampu merencanakan penyelesaian, pada aspek melaksanakan rencana adalah 79,62\%, peserta didik mampu melaksanakan rencana, dan pada aspek memeriksa kembali adalah 68,51\%, peserta didik mampu memeriksa kembali jawaban.

Penyebab kesalahan peserta didik pada penelitian ini yaitu : peserta didik masih belum teliti dalam menentukan satuan dari jawaban yang diberikan, kurang memanfaatkan waktu dalam mengerjakan soal, lupa mengerjakan beberapa tahapan pemecahan masalah, tidak memahami tentang materi sistem persamaan linier tiga variabel, dan masih belum paham sepenuhnya metode subsitusi dan metode eliminasi yang digunakan untuk mengerjakan soal.

Saran dari peneliti yaitu penelitian ini hanya berfokus pada 5 kriteria kemampuan yaitu kriteria sangat baik kriteria baik, kriteria cukup, kriteria kurang, dan kriteria sangat kurang, oleh karena itu peneliti selanjutnya dapat mengembangkan lagi menjadi beberapa kriteria yang lebih spesifik .

\section{Daftar Rujukan}

Argarini, D. F., Budiyono, \& Sujadi, I. 2014. Karakteristik Berpikir Kreatif Siswa Kelas VII SMP N 1 Kragan Dalam Memecahkan dan 
Mengajukan Masalah Matematika Materi Perbandingan Ditinjau Dari Gaya Kognitif. JMEE, 4 (2).

Marsitin, R. 2018. Kemampuan Berpikir Matematis Dalam Pembelajaran Discovery Link Map Pada Integral. Makalah disajikan pada Conference on Innovation and Application of Science and Technology (CIASTECH 2019), 1 (1).

Mawaddah, Siti \& Anisah, Hanna. 2015. Kemampuan Pemecahan Masalah Matematis Siswa Pada Pembelajaran Matematika Dengan Menggunakan Model Pembelajaran Generatif (Generatif Learning) di SMP. EDU-MAT Jurnal Pendidikan Matematika, 3 (2).

Ramadhani, R. 2017. Peningkatan Kemampuan Pemahaman Konsep Dan Kemampuan Pemecahan Masalah Matematika Siswa SMA Melalui Guided Discovery Learning Berbantuan Autograph. JPPM, 10 (2).
Rosdianwinata, E. 2015. Penerapan Metode Discovery Untuk Meningkatkan Kemampuan Pemecahan Masalah Matematika Siswa. MENDIDIK: Jurnal Kajian Pendidikan dan Pengajaran, 1 (1).

Sutikno, A. 2017. Efektifitas Program R Untuk Membantu Pengajar Dalam Mengkoreksi Jawaban Siswa Pada Soal Matematika Matriks Secara Cepat dan Benar. Research Fair UNISRI, 1(1).

Yulianto, G.D., Suastika, I K., \& Fayeldi, T. 2019. Analisis Kemampuan Pemecahan Masalah Matematika Berdasarkan Langkah Polya Pada Materi Sistem Persamaan Linear Dua Variabel Kelas VIII SMP PGRI 4 Kalipare Malang. Pi: Mathematics Education Journal. 2 (1). 